\title{
Neurochemical coding in the small intestine of patients with Crohn's disease
}

\author{
A Belai, P B Boulos, T Robson, G Burnstock
}

Department of

Anatomy and

Developmental

Biology

A Belai

T Robson

G Burnstock

Department of Surgery,

University College

London Medical

School,

London

P B Boulos

Correspondence to: Dr A Belai,

Department of Anatomy and

Developmental Biology,

University College London

Gower Street,

London WC1E 6BT.

Accepted for publication 20 February 1997

\begin{abstract}
Background-There have been conflicting results regarding the effect of Crohn's disease on the neurochemical composition of the enteric nervous system.
\end{abstract}

Aims-To examine the effect of Crohn's disease on the neurochemical composition of enteric nerve fibres and cell bodies using whole mount preparations of human ileum.

Methods-Whole wall ileum from seven normal subjects and nine patients with Crohn's disease was used to investigate the neurochemical composition of neurones and nerve fibres in the myenteric plexus, circular muscle, and serosa layer of ileum using immunohistochemical techniques.

Results-Increased tyrosine hydroxylase, 5-hydroxytryptamine, and neuropeptide $Y$ immunoreactivity was exclusively seen in the myenteric plexus. There was increased neurofilament immunoreactivity in the myenteric plexus and nerve fibres of the circular muscle layer, and thick bundles of immunoreactive nerve fibres in the serosa layer. Increased vasoactive intestinal polypeptide, nitric oxide synthase, and pituitary adenylate cyclase activating peptide immunoreactivity was seen in the myenteric plexus and nerve fibres of the circular muscle layer, and aggregates of inflammatory cells in the serosa layer of the afflicted segment of Crohn's ileum. In addition, there was a chaotic display of nerve fibres containing some of the neuroactive substances with a high frequency of enlarged varicosities in the myenteric ganglia and/or nerve fibres of the circular muscle layer of Crohn's ileum.

Conclusion-Results show quantitative as well as qualitative changes in the neurochemical composition of enteric nerve fibres and nerve cell bodies of Crohn's ileum. These changes and the presence of nitric oxide synthase and peptides immunoreactive inflammatory cells in the serosa layer suggest that nerve-immune interactions may have a significant role in the process of the inflammatory changes seen in Crohn's ileitis.

(Gut 1997; 40: 767-774)

Keywords: Crohn's disease, tyrosine hydroxylase, 5-hydroxytryptamine, nitric oxide, peptides, enteric nerves.
Crohn's disease (CD) has been described as a chronic form of intestinal inflammation which is segmental, transmural, and granulomatous. ${ }^{1}$ It affects any part of the intestine, but most commonly it occurs in the distal small bowel and proximal part of the colon. ${ }^{2}$ As the disease progresses fibrosis develops, causing thickening of the bowel wall and progressive stasis leading to distension proximal to the affected area, eventually resulting in obstruction. ${ }^{3}$ Early histopathological studies by Davies et $a l^{4}$ suggested increased numbers of myenteric ganglion cells in Crohn's ileitis. Axonal necrosis $^{5}$ and ganglion cell degeneration ${ }^{6} 7$ have also been observed using light microscopy and ultrastructural studies. Reports from early studies of the neurochemical composition of enteric neurones and nerve fibres in $C D$ present conflicting findings. By immunohistochemical and radioimmunoassay techniques, an increase in vasoactive intestinal polypeptide (VIP) containing nerves has been reported in transmural intestinal specimens ${ }^{8}$ and rectal biopsy specimens ${ }^{9}$ of patients with CD. On the other hand, Koch et al ${ }^{10}$ reported a significant decrease in the concentration of VIP in the mucosa and smooth muscle of colon from patients with CD. Electrophysiological studies by the same group have shown a reduced intrinsic inhibitory neural input to the circular smooth muscle cells of colon from patients with $C D$, suggesting an association between the reduced intrinsic inhibitory neural input and the decreased tissue content and immunostaining of VIP in Crohn's colitis. ${ }^{11}$

Contrary to the above conflicting reports, an immunohistochemical study by Sjölund $e t a l^{12}$ showed no change in the distribution and frequency of VIP, substance $P$, and enkephalin containing nerve fibres in patients with $C D$ compared with controls, except for coarse appearance of the peptide immunoreactive nerve fibres in patients with CD. A comparative study on the effect of ulcerative colitis (UC) and CD on nitric oxide synthase (NOS) activity in the mucosa and muscle coat of the affected colon reported no change in NOS activity in both mucosa and muscle of the colon from patients with $C D$ compared with controls, with an eightfold increase in NOS activity in the colonic mucosa but not the muscle of the patients with UC. ${ }^{13}$ However, recent work by Rachmilewitz et $a l^{14}$ showed enhanced colonic generation of oxides of nitrogen by stimulated NOS activity in the mucosa of patients with UC and CD and 
suggested that this change may contribute to tissue injury seen in inflammatory bowel diseases. The aim of the present study was to investigate the effect of $\mathrm{CD}$ on the neurochemical composition of the afflicted region of the small intestine using whole mount preparations of the gut rather than sections, in order to show the in situ distribution and organisation of nerve fibres and nerve cell bodies containing tyrosine hydroxylase (TH), 5-hydroxytryptamine (5-HT), the peptides VIP, and neuropeptide Y (NPY), pituitary adenylate cyclase activating peptide (PACAP), NOS, the enzyme responsible for the synthesis of nitric oxide (NO), and neurofilaments (NF).

\section{Methods}

TISSUE SAMPLES

Specimens of normal and diseased gut were obtained from the antimesenteric border of intestine immediately after removal at operation. For control samples, gross and microscopically normal areas of terminal ileum were obtained from patients undergoing surgery for cancer of the ascending colon $(n=5$, median age 55, range 42-71) and of duodenum from patients undergoing surgery for cancer of the stomach (antral, $n=2$, median age 57). Diseased bowel specimens were obtained from patients with CD $(n=9$, median age 32, range 19-47). All tissue specimens from patients with $C D$ displayed signs of active intestinal inflammation and specimens used were from macroscopically afflicted segments of the intestine. The inflammatory changes included infiltration of the stromal connective tissue by inflammatory cells, and thickening of the lamina propria and submucosa. No tissue specimens were used from adjacent nonafflicted regions of the intestine. These studies were approved by the Joint University College/ University College Hospital Committee on Ethics of Human Research.

\section{TISSUE PROCESSING}

\section{Whole mount preparations}

Whole mount preparations of the gut have been shown to provide a more comprehensive visual assessment of the distribution of enteric neuroactive substances showing the overall in situ arrangement of the enteric neuronal elements which is not possible with frozen section preparations. Whole wall specimens were taken and pinned out on Sylgard silicone rubber and fixed in 4\% paraformaldehyde in phosphate buffered saline (PBS) for four to six hours at $4^{\circ} \mathrm{C}$. After fixation tissue specimens were washed three times for 20 minutes each time in PBS containing $1 \%$ Triton X-100. The different layers of the gut - namely, the serosa, the outer muscular coat, and the mucosa layers, were separated using a dissecting microscope and a small pair of scissors. The myenteric plexus was exposed by carefully peeling off the thick circular muscle coat leaving the plexus attached to the longitudinal muscle layer. At this stage a small piece of each segment of the intestine was stained with toluidine blue to check possible disruption of the myenteric plexus during dissection. Tissue segments with major disruption were discarded and the rest were stored in PBS containing $0 \cdot 1 \%$ sodium azide until immunostaining.

\section{Frozen section preparations}

Parts of the stretched and fixed tissue specimens were cut, removed from the Sylgard and washed three times each for 20 minutes in PBS containing $30 \%$ sucrose, followed by an overnight wash in the same solution at $4^{\circ} \mathrm{C}$ and processed for frozen section preparations. The reasons for having parallel whole mount and frozen section preparations of the same segment of the gut were: to double check that the microdissection to expose the myenteric plexus did not cause an artefact; and qualitatively and quantitatively to analyse the density of fibres in the muscular coats, especially in the circular muscle layer of the intestine. Cryostat sections of $15 \mu \mathrm{m}$ thickness were then cut in both longitudinal and transverse orientations for immunostaining. The pattern of distribution of neurones and nerve fibres containing NF immunoreactivity in the myenteric plexus of control and CD ileum was examined using frozen section rather than whole mount preparations.

\section{Immunohistochemistry}

Both whole mount and frozen section preparations were incubated in PBS containing $10 \%$ non-immune goat serum for one hour and stained using the indirect immunostaining procedure. Briefly, the tissue preparations were incubated overnight at room temperature with antiserum raised in rabbit against TH (Affiniti, Exeter, UK), 5-HT (Incstar, Wokingham, Cambridge, UK), VIP (Incstar), NPY (Biogenesis, Poole, UK), PACAP (Peninsula, Belmont, California), neuronal type NOS (nNOS) (B 220-1, Euro-Diagnostica, Malmo, Sweden) and monoclonal antimouse NF (Amersham Ltd, UK) antibody. All antibodies except anti-5-HT $(1 / 500)$ were used at a dilution of $1 / 1000$. Control experiments to determine antibody specificity were performed by preincubating all the antibodies used with the appropriate antigen. After exposure to the primary antiserum, the tissue preparations were washed in PBS containing $0.1 \%$ Triton $\mathrm{X}-100$ three times each for 10 minutes and incubated for two hours with biotinylated goat antirabbit and horse antimouse (for NF) IgG (Amersham), followed by streptavidin fluorescein (Amersham) for one hour at room temperature. The preparations were then washed and mounted in buffered glycerol $(\mathrm{pH} \mathrm{8.6)}$ ) for fluorescence microscopy. The whole mount preparations were counterstained with $1 \%$ pontamine sky blue ${ }^{15}$ to reduce background fluorescence.

Frequency of immunoreactive neurones was analysed by counting neurones in two 
preparations (whole mount or sections) of each specimen. Six ganglia were randomly selected from each preparation and the mean number of neurones per ganglion was calculated. The data from control and CD specimens were then subjected to statistical analysis.

Image analysis

The Seescan image processing system (Seescan Imaging Ltd, Cambridge, England) was used to assess the density of immunoreactive nerve fibres in circular muscle of the intestine. The area of the thick circular muscle layer in all preparations was computer analysed using a $10 \%$ objective that allowed a large area of the muscle to be assessed and thus reduced field selection errors. The area of the region was broadly uniform which ensured reproducibility of the values obtained.

Computer assisted image analysis converted the image into binary form corresponding to
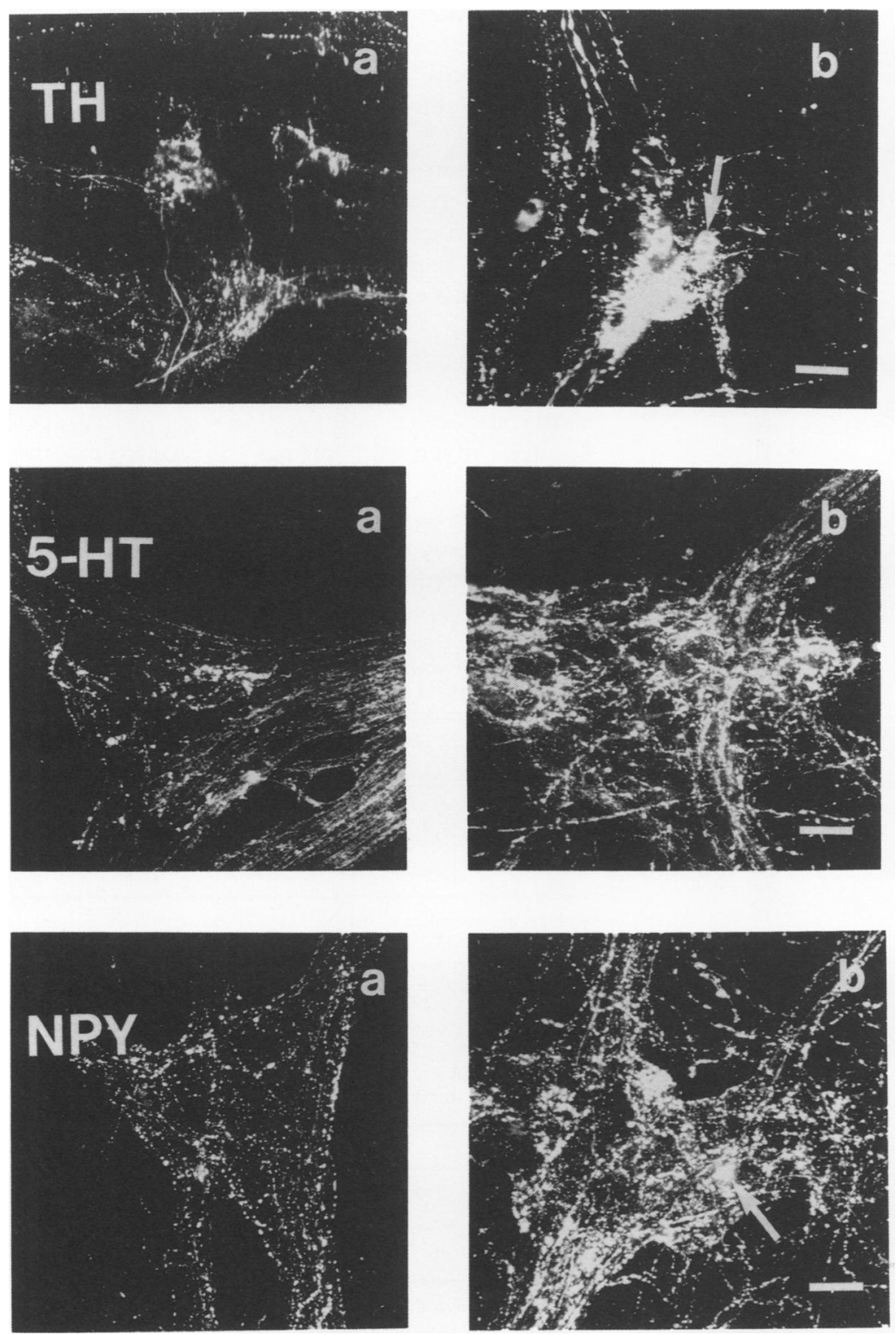

Figure 1: Micrographs showing TH, 5-HT, and NPY immunoreactive nerve fibres and nerve cell bodies in the myenteric plexus of small intestine from controls (a) and patients with Crohn's disease (b). Arrows in micrographs TH-b and NPY-b indicate nerve cell bodies in the ganglia. Calibration bars $=30 \mu \mathrm{m}$. positive or negative immunofluorescence. An optical density threshold was set to remove background labelling, and the resultant fluorescent area was divided by the total area of the circular muscle to give a positive to negative immunofluorescence ratio.

\section{Statistical analysis}

The number of neurones and density of immunoreactive nerve fibres in the circular muscle layer of the intestine are given as mean (SEM), and the differences in mean values between $C D$ and normal ileum were tested by the unpaired two-tailed Student's $t$ test. A level of probability of less than 0.05 was considered to be significant.

\section{Results}

TYROSINE HYDROXYLASE

Nerve fibres containing $\mathrm{TH}$ immunoreactivity were seen in the myenteric plexus of normal segments of ileum (Fig 1, TH-a). Varicose nerve fibres were present in the internodal strands that ran between myenteric ganglia, and in secondary and tertiary branches of the myenteric plexus. There were no TH immunoreactive nerve cell bodies in the myenteric ganglia of the control ileum preparations. In the myenteric plexus of the CD ileum, the main difference in the pattern of distribution of TH immunoreactivity was the presence of numerous small $\mathrm{TH}$ immunoreactive nerve cell bodies usually found in clusters at one or the other end of the myenteric ganglia (Fig 1, TH-b). Some of the ganglia displayed immunoreactive nerve fibres arranged in disarray across the ganglia. This feature was seen mainly in those ganglia which did not contain immunoreactive nerve cell bodies (not shown). In the circular muscle layer of the control ileum, varicose fibres containing $\mathrm{TH}$ immunoreactivity were infrequent and there was no change in the density of these fibres in CD ileum (not shown).

\section{-5-HYDROXYTRYPTAMINE}

In the normal ileum, 5-HT immunoreactive nerve fibres were found mainly in the myenteric ganglia and internodal strands but not in the secondary and tertiary branches of the plexus (Fig 1, 5-HT-a). In the present study, 5-HT immunoreactive nerve cell bodies were not seen in either the control or CD preparations, possibly owing to the limitation of the sensitivity of the technique used, as 5-HT containing enteric nerves are known to be of intrinsic origin. ${ }^{16}$ The myenteric ganglia of ileum from patients with CD had more 5-HT immunoreactive nerve fibres than that from controls (Fig 1, 5-HT-b). The varicose nerve fibres in the ganglia of $C D$ ileum, however, lacked the usual orderly arrangement, displaying a prominent feature of disarray in all the diseased preparations examined (Fig 1, 5-HT-b). 5-HT immunoreactive nerve fibres were not seen in the 
circular muscle layer of either control or diseased ileum examined.

\section{NEUROPEPTIDE Y}

Immunoreactive nerve fibres containing NPY were seen in the primary, secondary, and tertiary branches of the myenteric plexus of the control ileum preparations (Fig 1, NPY-a). Very few immunoreactive nerve cell bodies were seen in the control preparations (see Table II). In the myenteric ganglia of the CD ileum, there was an increase in the density of NPY immunoreactive nerve fibres, with irregular distribution of nerve fibres throughout the ganglia (Fig 1, NPY-b). In addition, a significant $(\mathrm{p}<0 \cdot 02)$ increase in the number of NPY immunoreactive nerve cell bodies was seen in the diseased preparations compared with controls (Fig 1, NPY-b). In the circular muscle layer of the control ileum, varicose fibres containing NPY immunoreactivity were seen rarely and there was no change in the
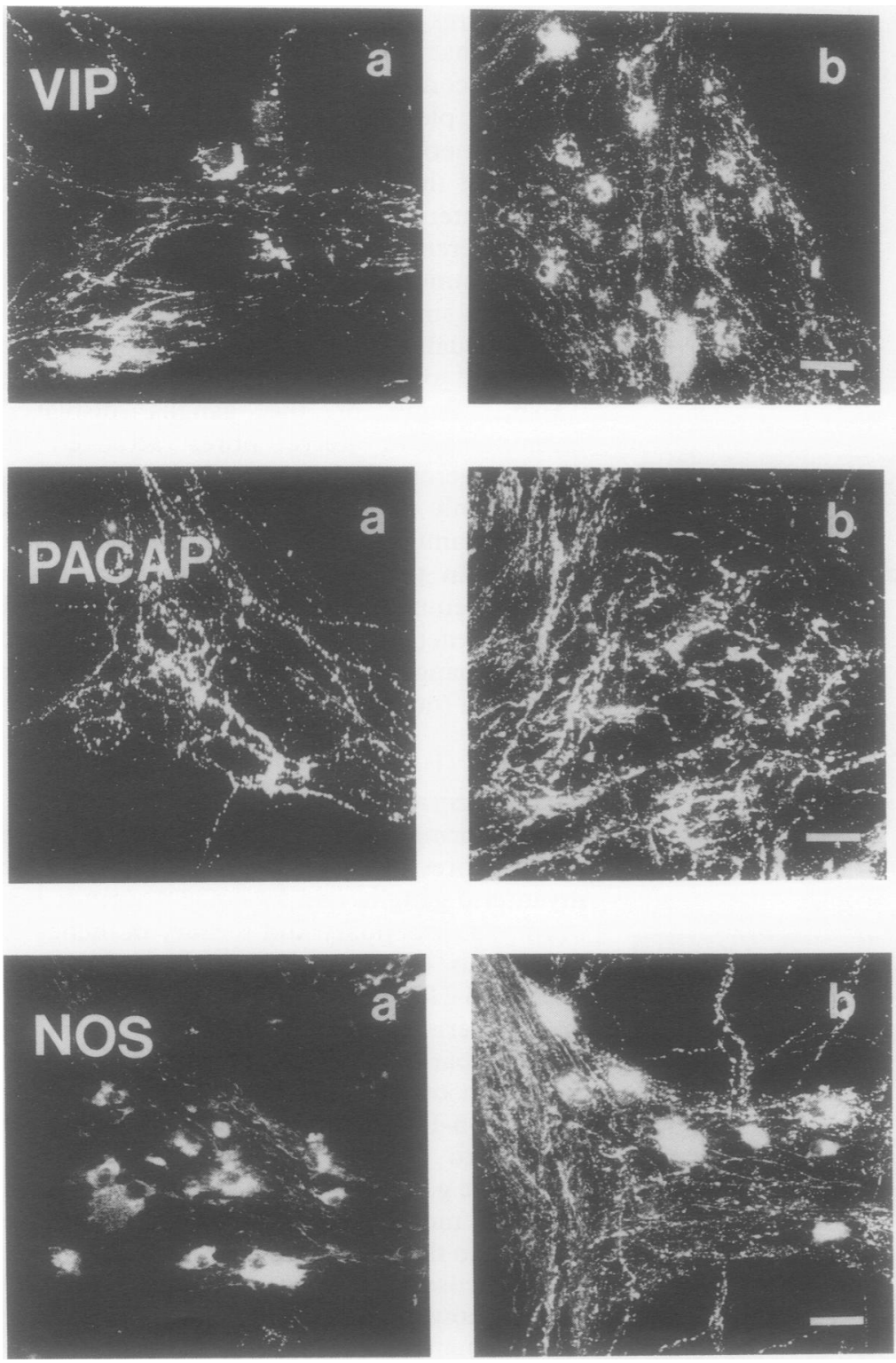

Figure 2: Micrographs showing VIP, PACAP, and NOS immunoreactive nerve fibres and nerve cell bodies in the myenteric plexus of small intestine from controls (a) and patients with Crohn's disease (b). Calibration bars $=30 \mu \mathrm{m}$. density of these fibres in CD ileum (not shown).

VASOACTIVE INTESTINAL POLYPEPTIDE

VIP immunoreactive nerve cell bodies and nerve fibres were found in the myenteric plexus of control ileum preparations (Fig 2, VIP-a). A significant $(p<0.001)$ increase in the number of VIP immunoreactive nerve cell bodies and increased density of immunoreactive nerve fibres were seen in the CD preparations (Fig 2 , VIP-b). The chaotic distribution of nerve fibres seen in 5-HT and NPY immunostained diseased preparations was not seen in VIP immunostained preparations.

There were numerous VIP immunoreactive nerve fibres in the circular muscle layer of control ileum (Fig 3, VIP-a). In the circular muscle layer of $C D$ ileum, there was a significant $(p<0.001)$ increase in the density of VIP immunoreactive nerve fibres compared with controls (Fig 3, VIP-b). Almost all the immunoreactive nerve fibres in the diseased ileum had a coarse appearance, and the distribution of the nerve fibres was more regular and orderly than that of NOS immunoreactive nerve fibres (Fig 3, VIP-b, NOS-b).

In the serosa layer of Crohn's ileum there were numerous inflammatory cells stained for VIP immunoreactivity (Fig 4, d). These cells were not seen in any of the control ileum preparations examined.

PITUITARY ADENYLATE CYCLASE ACTIVATING PEPTIDE

In the myenteric plexus of control ileum preparations, PACAP immunoreactive nerve fibres were found in moderate quantity, in the primary, secondary, and tertiary branches of the plexus (Fig 2, PACAP-a). PACAP

TABLE I Number of immunoreactive neurones in the myenteric ganglia of control and Crohn's ileum

\begin{tabular}{lll}
\hline Marker & $\begin{array}{l}\text { Controls }(n=5) \\
\text { (neurones/ganglia) }\end{array}$ & $\begin{array}{l}\text { Crohn's }(n=7) \\
\text { (neurones/ganglia) }\end{array}$ \\
\hline VIP & $2 \cdot 45(0.49)$ & $7 \cdot 89(0 \cdot 07)$ \\
NOS & $4 \cdot 73(0 \cdot 20)$ & $7.65(1.03) \dagger$ \\
NF & $3.79(0.14)$ & $6.55(1.21) \dagger$ \\
NPY & $0.31(0.01)$ & $1.03(0 \cdot 14) \ddagger$ \\
\hline
\end{tabular}

Results expressed as mean (SEM). VIP, vasoactive intestinal polypeptide; NOS, nitric oxide synthase; NF, neurofilaments; NPY, neuropeptide Y. ${ }^{\star} p<0.001 ; \neq p<0.01 ; \neq p<0.02$.

TABLE II Image analysis showing density of immunoreactive nerve fibres in the circular muscle coat of control and Crohn's ileum

\begin{tabular}{lll}
\hline Marker & Controls $(n=5)$ & Crohn's $(n=5)$ \\
\hline NF & $2 \cdot 21(0 \cdot 64)$ & $6.45(1 \cdot 07) \dagger$ \\
VIP & $1.39(0 \cdot 21)$ & $5 \cdot 09(0 \cdot 82)^{\star}$ \\
NOS & $2.06(0.53)$ & $6.97(0 \cdot 78)^{\star}$ \\
PACAP & $0.85(0.07)$ & $4 \cdot 06(1.01) \ddagger$ \\
\hline
\end{tabular}

The figures show the mean (SEM) values of fluorescent density per defined area for each marker. The fluorescent area was divided by the total area of the thickened circular muscle to give a positive to negative immunofluorescence ratio. NF, to give a positive to negative immunofluorescence ratio. NF,
neurofilaments; VIP, vasoactive intestinal polypeptide; NOS,
nitric oxide synthase; PACAP, pituitary adenylate cyclase activating peptide. ${ }^{\star} \mathrm{p}<0.001 ; \mathrm{tp}<0.01 ; \neq \mathrm{p}<0.05$. 
immunoreactive nerve cell bodies were extremely rare in both control and diseased preparations. In the myenteric plexus of CD ileum, there was an increase in PACAP immunoreactive nerve fibres, with prominent irregular arrangement of the fibres throughout the ganglia (Fig 2, PACAP-b).

Varicose nerve fibres containing PACAP immunoreactivity were also found throughout the thickness of the circular muscle layer of the control ileum preparations (Fig 4, PACAP-a). In the CD ileum, the density of these fibres was significantly $(p<0.05)$ increased and similar to NOS and NF immunoreactive nerve fibres. PACAP immunoreactive nerve fibres displayed irregular distribution in all CD ileum preparations examined (Fig 4, PACAP-b).

Inflammatory cells stained for PACAP immunoreactivity were seen in the serosa layer of the diseased ileum (Fig 4, f) but not in any of the control ileum preparations examined.
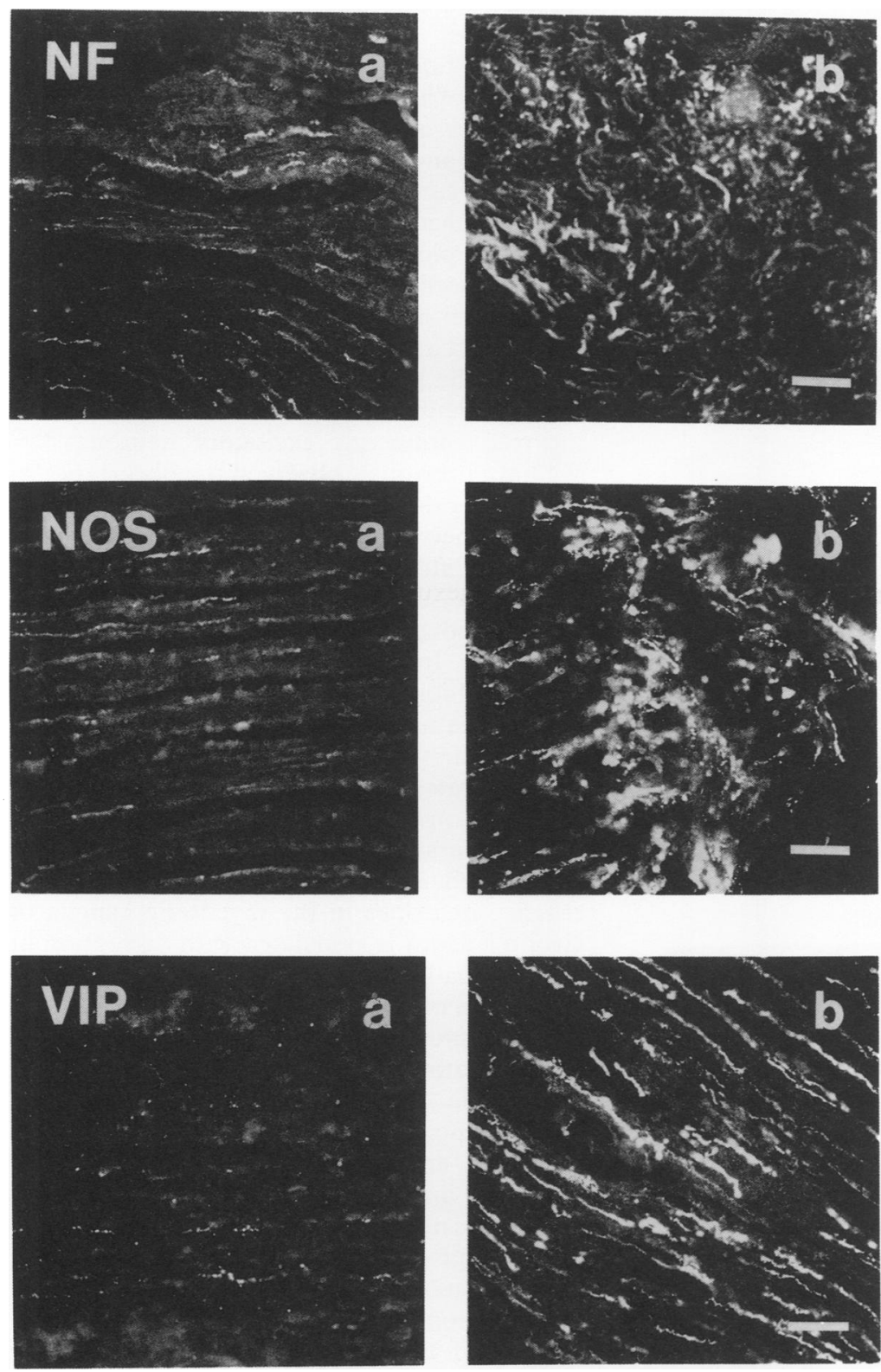

Figure 3: Micrographs showing NF, NOS, and VIP immunoreactive nerve fibres in the circular muscle layer of small intestine from controls (a) and patients with Crohn's disease (b). Calibration bars $=20 \mu \mathrm{m}$.
NITRIC OXIDE SYNTHASE

Immunoreactive nerve cell bodies and fibres containing NOS were seen in the myenteric plexus of control ileum preparations (Fig 2, NOS-a). In the myenteric plexus of CD ileum, there was an increase in NOS immunoreactive nerve fibres and nerve cell bodies $(p<0.01)$ compared with controls (Fig 2, NOS-b). As with VIP immunoreactive nerve fibres, there was no obvious sign of disarray of NOS immunoreactive nerve fibres in the myenteric ganglia of CD ileum (Fig 2, VIP-b, NOS-b).

Moderate numbers of NOS immunoreactive nerve fibres were seen in the circular muscle layer of the control ileum (Fig 3, NOS-a). The density of NOS immunoreactive nerve fibres was significantly $(p<0.001)$ increased in CD intestine compared with control (Fig 3, NOS-b). Almost all the fibres had a coarse appearance and had irregular distribution throughout the segment of the muscle examined (Fig 3, NOS-b).

In the serosa layer of Crohn's ileum, a very high number of inflammatory cells stained for neuronal type NOS were seen (Fig 4, e). These cells were not found in any of the control ileum preparations examined.

NEUROFILAMENTS

In the myenteric plexus of control ileum there were NF immunoreactive nerve cell bodies and fibres throughout the preparations (Fig 4, $\mathrm{NF}-\mathrm{a})$. Increases in the density of nerve fibres and frequency of nerve cell bodies $(p<0.01)$ were seen in the myenteric plexus of $C D$ ileum (Fig 4, NF-b). The immunoreactive nerve fibres in the myenteric plexus displayed a slightly irregular distribution compared with controls (Fig 4, NF-b).

In the circular muscle layer of the control ileum there were several NF immunoreactive nerve fibres (Fig 3, NF-a). A significant $(p<0.01)$ increase in the density of NF immunoreactive nerve fibres was seen in the CD ileum (Fig 3, NF-b). The orientation of the fibres in the CD ileum was irregular and most of the fibres had a coarse appearance (Fig 3, NF-b).

In the serosa layer of Crohn's ileum, abundant nerve fibre bundles containing NF immunoreactivity were also seen but these were not present in the control ileum preparations (Fig 4, c).

Table I lists the changes seen in the immunoreactive neurones and Table II presents the image analysis results for the density of immunoreactive nerve fibres.

\section{Discussion}

The data generated in the present study have shown the presence of extensive and widespread changes in the neurochemical composition of myenteric nerves and nerve fibres in the circular muscle layer, and infiltration of peptides and NOS immunoreactive inflammatory cells in the serosa layer of CD ileum. On the whole the present data 
can be broadly divided into three categories of changes.

The first category, which involves increased TH, 5-HT, and NPY immunoreactivity, is characterised by changes exclusively seen in the myenteric plexus. Nerve fibres containing $\mathrm{TH}, 5-\mathrm{HT}$, and NPY immunoreactivity have
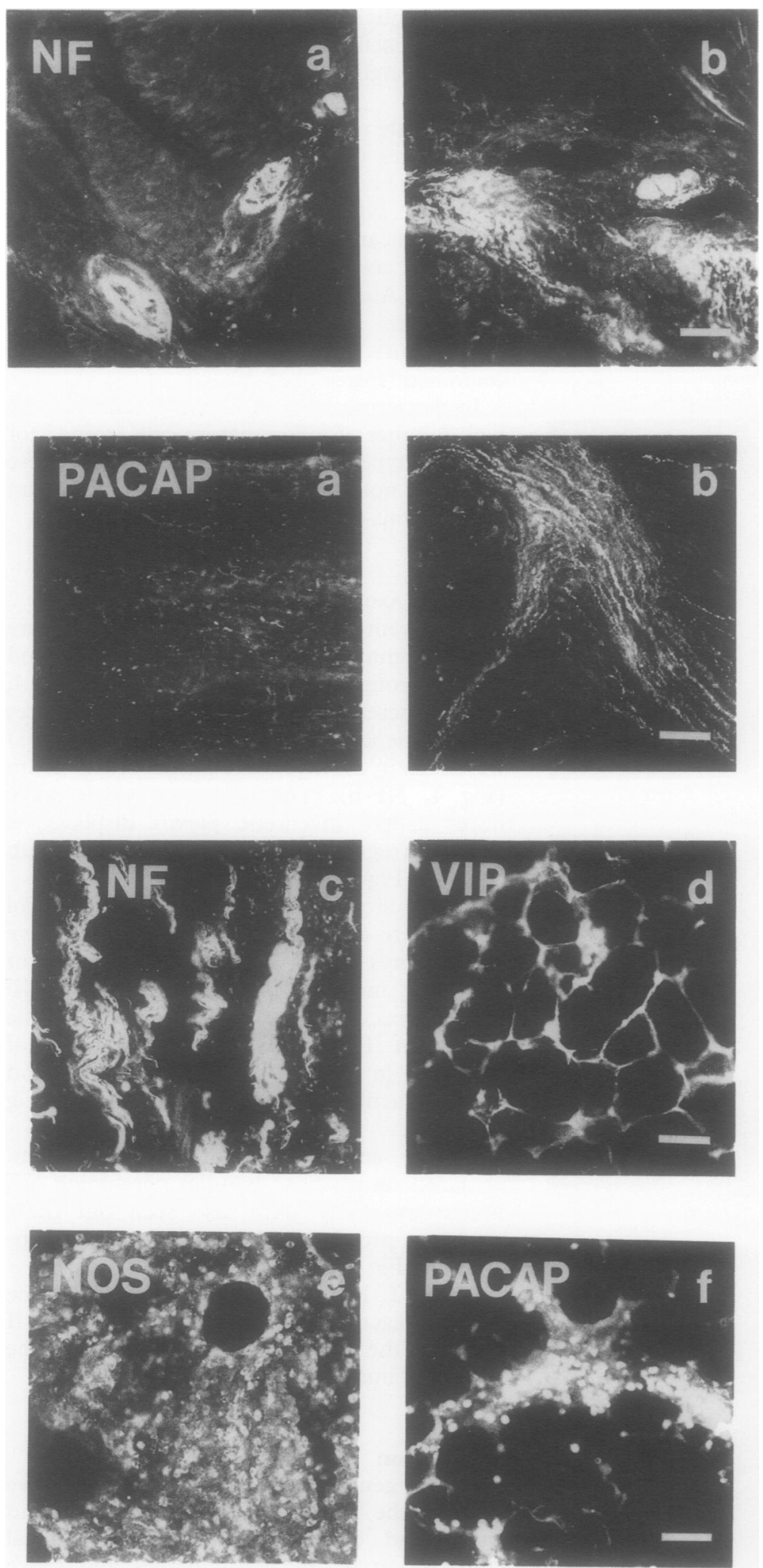

Figure 4: Micrographs showing NF immunoreactivity in the myenteric ganglia and PACAP immunoreactive nerve fibres in the circular muscle layer of small intestine from controls (a) and patients with Crohn's disease (b); and NF immunoreactive nerve bundles $(c), V I P(d), N O S(e)$ and PACAP $(f)$ immunoreactive inflammatory cells in the serosa layer of Crohn's ileum. Calibration bars $=20 \mu \mathrm{m}$. been reported to be either sparsely distributed or absent in the muscularis externa of human small bowel ${ }^{17-22}$ (our own results in the control ileum also support this); this is consistent with the present findings that the changes in these nerve types are confined to the myenteric plexus of Crohn's ileum. The presence of chaotic distribution of the immunoreactive nerve fibres in the myenteric ganglia and high frequency of enlarged varicosities are the other common features of changes in these nerve types. Previous studies by Dvorak et $a l^{5}$ and Dvorak and Silen ${ }^{7}$ reported axonal necrosis in the small bowel of patients with $C D$, and suggested that the injured axons belong to the sympathetic nervous system..$^{57}$ In the present study, the noradrenergic nerve fibres (as localised by $\mathrm{TH}$ immunoreactivity) in the myenteric ganglia of Crohn's ileum had a high incidence of enlarged varicosities. As the presence of enlarged varicosities in enteric nerves has been described for degenerating adrenergic nerves in chemically sympathectomised rat intestines, ${ }^{23}$ it is conceivable that our results are consistent with the ultrastructural findings of Dvorak and Silen. ${ }^{7}$ The presence of small $\mathrm{TH}$ immunoreactive nerve cell bodies in the myenteric ganglia of $\mathrm{CD}$ ileum is another intriguing finding in the present study. The presence of $\mathrm{TH}$ immunoreactive nerve cell bodies in the myenteric plexus of normal human small bowel has not been reported previously. Noradrenergic nerves in the intestine are known to exert their effect on the motility of non-sphincter parts of the gut within the myenteric ganglia through inhibition of transmitter release from intrinsic cholinergic excitatory neurones. ${ }^{24} 25$ We have previously observed the occurrence of $\mathrm{TH}$ and/or dopamine- $\beta$-hydroxylase immunoreactive nerve cell bodies in the myenteric ganglia of streptozotocin-diabetic rat intestine and in the small intestine of rats treated with 6-hydroxydopamine (Belai, unpublished observation). In both cases the adrenergic nerve fibres exhibited an incidence of enlarged varicosities and the density of the immunoreactive nerve fibres in the streptozotocindiabetic rats was progressively reduced with the duration of diabetes, suggesting a process of degenerative changes. ${ }^{26}$ It is therefore possible that the presence of TH immunoreactive neurones in the myenteric ganglia of Crohn's ileum is associated with disruption of the sympathetic innervation triggering the expression of TH by neurones which normally do not express that enzyme.

It is known that 5-HT stimulates both cholinergic excitatory and non-adrenergic, non-cholinergic (NANC) inhibitory neurones in the gut, and it is suggested that serotonergic neurones are probably interneurones within the enteric nervous system. ${ }^{16}$ Furthermore, one of the proposed roles of NPY in the mammalian gut is modulation of smooth muscle contractions by prejunctional inhibition of cholinergic motor nerves. ${ }^{27} 28$ It is interesting to note that in the present study those neurotransmitters that are known to act presynaptically on the myenteric cholinergic 
motor neurones present similar changes in Crohn's ileitis. As noradrenaline and NPY are known to inhibit, while 5-HT stimulates, transmitter release from cholinergic neurones in the myenteric ganglia, the apparent increase in nerve fibres containing neurotransmitters of opposing actions on cholinergic neurones in Crohn's ileum is intriguing. The possible contribution of these changes to the reported abnormal motor activity ${ }^{29}$ in patients with CD merits further examination.

The second category of changes is characterised by increased NF immunoreactivity in the myenteric plexus and nerve fibres of the circular muscle layer, and the presence of thick bundles of immunoreactive nerve fibres in the serosa. Although the exact function of neurofilaments is not known, NF immunoreactivity has been reported in a subpopulation of myenteric neurones in both the rat $^{30}$ and guinea pig $^{31}$ intestines. Similarly we only found NF in a subpopulation of myenteric neurones of the control human ileum preparations. Accumulation of neurofilaments in neuronal structures has been generally associated with axonal neuropathy. Schimdt et $a l^{32}$ showed the presence of swollen terminal axons containing large numbers of disorganised neurofilaments in the superior mesenteric ganglia of diabetic patients. They suggested that this pathological lesion may be attributed to the autonomic dysfunction commonly observed in diabetic patients. $^{32}$ It is therefore possible that the increased NF immunoreactive neurones and nerve fibres observed in the present study are indicative of disruption of the autonomic innervation of CD ileum.

The third category of changes was seen in nerve fibres that are reported to contain mediators of NANC inhibitory neurotransmission in the intestines of most mammalian species including humans. It involves increased VIP, NOS, and PACAP immunoreactivity and is characterised by changes in the myenteric plexus and circular muscle layer, and the presence of aggregates of inflammatory cells containing VIP, NOS, and PACAP immunoreactivity in the serosa layer. Although there is an overall similarity of changes in all three, PACAP immunoreactive nerve fibres, unlike the other two, present irregular distribution in the myenteric plexus and circular muscle coat of Crohn's ileum. In keeping with our findings, Bishop et $a l^{8}$ and O'Morain et $a l^{9}$ reported an increase in the density of nerve fibres and tissue content of VIP immunoreactivity in the gut wall of patients with $C D$. One of the features of changes in VIP immunoreactivity that has not been reported previously is the dramatic increase in the number of VIP immunoreactive nerve cell bodies in the myenteric ganglia of Crohn's ileum. This dramatic increase in myenteric neurones containing VIP, NOS, and PACAP immunoreactivity is likely to be indicative of an overall increase in the production of the respective substances in Crohn's ileitis. Considering the proposed role of VIP, NO, and PACAP in NANC inhibitory enteric neurotransmission, the increased production of these substances may cause a persistent relaxation of the smooth muscle of the afflicted segment of Crohn's ileum provided that the post-synaptic site is intact. A decrease in NOS producing neurones and nerve fibres has been previously reported in abnormalities leading to persistent contraction in achalasia, ${ }^{33}$ infantile hypertrophic pyloric stenosis, ${ }^{34}$ and Hirschsprung's disease. ${ }^{35} \mathrm{~A}$ recent study by Cortesini et $a^{36}$ reported increased NOS positive neurones in both plexuses of the colon from patients with idiopathic chronic constipation, suggesting that the excess production of NO may be responsible for the inhibition of the giant migrating contractions in the colon of these patients. ${ }^{36}$ It is therefore conceivable that the changes in NOS, VIP, and PACAP immunoreactivity seen in the present study are likely to affect the NANC inhibitory neurotransmission and hence contribute to the reported abnormal motor activity ${ }^{29}$ in patients with CD.

Another interesting finding is the infiltration of inflammatory cells that are VIP, NOS, and PACAP immunoreactive in the serosa layer of the afflicted segment of Crohn's ileum. Infiltration of the neuromuscular layers of Crohn's intestine by inflammatory cells has long been recognised, and cell types such as macrophages, plasma cells, lymphocytes, and mast cells have been reported in the plexuses of CD intestines. ${ }^{5}$ To our knowledge, however, this is the first demonstration of the presence of inflammatory cells that are immunoreactive to known neuroactive substances in the serosa layer of Crohn's ileum. It has been reported that some cases of pseudo-obstruction, particularly those associated with the paraneoplastic syndrome, are associated with lymphoid infiltration of the muscularis externa or myenteric plexus. ${ }^{37}{ }^{38}$ Geboes et al ${ }^{39}$ confirmed lymphocytic infiltration of the enteric nervous system in CD and demonstrated expression of MHC class II antigen by the glial cells of the enteric nervous plexus. Occasionally, MHC class II antigen expression was found to be associated with axonal swelling or depletion of axonal organelles, suggesting that damage to the enteric nervous system may be immunologically mediated in patients with $\mathrm{CD} .{ }^{39}$ What is more intriguing is the fact that the NOS isoform expressed in the inflammatory cells is of neuronal type rather than the inducible isoform which is known to be present in this type of cell..$^{40}$ Although the possibility of cross reactivity of the two isoforms of NOS cannot be ruled out, the fact that similar cells were not seen in any of the other layers of the CD ileum including the mucosa layer (Belai, unpublished observation) makes cross reactivity the least possible explanation. The implication of this finding is not clear except that the activity of NOS in these cells may be calcium dependent. Possibly most if not all the inflammatory cells seen in the serosa layer may be mast cells as a large component of the activity of NOS in mast cells has been reported to be calcium dependent. ${ }^{40}$ Whether or not the inflammatory cells in the present preparations are mast cells, however, needs to be verified 
using specific markers. There is increasing evidence for nerve-immune interactions of which several molecules have been suggested to be candidate mediators for communication between inflammatory cells and nerves. In the intestine, a close proximity between mast cells and enteric nerves has been reported in the mucosa of normal rats where $8 \%$ of mast cells were found within $100 \mathrm{~nm}$ of neural processes and $11 \%$ between 101 and $500 \mathrm{~nm}$ of these structures. ${ }^{+2}$ The proportion of mast cells within $500 \mathrm{~nm}$ of neural processes was increased to $61 \%$ after infection of rats with the nematode Nippostrongylus brasiliensis, ${ }^{+2}$ clearly suggesting some form of interaction between mast cells and enteric nerves in response to infection.

In summary, the findings of the present study showed extensive changes seen in enteric nerves and infiltration of NOS and peptides immunoreactive inflammatory cells in the serosa layer of CD ileum, suggesting that nerve-immune interactions may play a significant part in the process of inflammatory changes seen in Crohn's ileitis. However, the exact mechanism(s) and degree of importance of the interactions in initiating and perpetuating the inflammatory process merit further investigation.

This work was funded by the Wellcome Trust Post Doctoral Fellowship to Dr A Belai. We are grateful to Mr P Hamlyn for invaluable information concerning supply of human specimens. We are also grateful to Professor N Williams and Mr M Hutton for making available the human specimens used in this study.

1 De Dombal FT. Definition of Crohn's disease. In: Pena AS, Wererman IT, Booth CC, Strober W, eds. Recent advances in Crohn's disease. Developments in Gastroenterology Vol 1. The Hague: Kluwer Academic, 1981: 3-6.

2 Goldberg HI, Caruthers SB, Nelson JA, Singleton JW. Radiographic findings of the national co-operative Crohn's disease study. Gastroenterology 1979; 77: 925-37.

3 Mekhiian HS, Switz DM, Melnvk CS, Rankin GB, Brooks RK. Clinical features and natural history of Crohn's RK. Clinical features and natural history
disease. Gastroenterology 1979; 77: 898-906.

4 Davies DR, Dockerty MB, Mayo CW. The myenteric plexus in regional enteritis: a study of the members of ganglion cells in the ileum in 24 cases. Surg Gynecol Obstet 1955; 101: 208-16.

5 Dvorak AM, Osage JE, Monhan RA, Dickersin GR. Crohn's disease: transmission electron microscopic studies. III. Target tissues: proliferation of and injury to smooth muscle and the autonomic nervous system. Hum Pathol 1980; 11: 620-34.

6 Riemann JF, Schmidt H. Ultrastructural changes in the autonomic nervous system following laxative abuse and other conditions. Scand $\mathcal{f}$ Gastroenterol 1982; 71(suppl): other cond

7 Dvorak AM, Silen W. Differentiation between Crohn's disease and other inflammatory conditions by electron microscopy. Ann Surg 1985; 201: 53-63.

8 Bishop AE, Polak JM, Bryant MG, Bloom SR, Hamilton $\mathrm{S}$. Abnormalities of vasoactive intestinal polypeptide containing nerves in Crohn's disease. Gastroenterolog 1980; 79: 853-60.

9 O'Morain C, Bishop AE, McGregor GP, Levi AJ, Bloom $\mathrm{SR}$, Polak JM, et al. Vasoactive intestinal peptide concentrations and immunocytochemical studies in rectal biopsies from patients with inflammatory bowel disease. Gut 1984; 25: 56-61.

10 Koch TR, Carney JA, Go VLW. Distribution and quantitation of gut neuropeptides in normal intestine and
inflammatory bowel diseases. Dig Dis Sci 1987; 32: inflamm.

11 Koch TR, Carney JA, Go VLW, Szurszewski JH. Altered inhibitory innervation of circular smooth muscle in inhibitory innervation of circular smooth musce

12 Siölund K, Schaffalitzky De Muckadell OB, Fahrenkrug J Håkanson R, Peterson BG, et al. Peptide-containing nerve fibres in the gut wall in Crohn's disease. Gut 1983; 24: 724-33

13 Boughton-Smith NK, Evans SM, Hawkey CCJ, Cole AT Balsitis M, Whittle BJ, et al. Nitric oxide synthase activity in ulcerative colitis and Crohn's disease. Lancet 1993 342: $338-40$.
14 Rachmilewitz D, Stamler JS, Bachwich D, Karmeli F, Ackerman Z, Podolsky DK. Enhanced colonic nitric oxide generation and nitric oxide synthase activity in ulcerative colitis and Crohn's disease. Gut 1995; 36: 718-23.

15 Cowen T, Haven AJ, Burnstock G. Pontamine sky blue: a counterstain for background autofluorescence in fluorescence and immunofluorescence histochemistry. Histochemistry 1984; 82: 205-8

16 Gershon MD. Enteric serotonergic neurones. In: Osborne NN, ed. Biology of serotonergic transmission. Chichester: Wiley, 1982: 363-99.

17 Capurso L, Friedmann CA, Parks AG. Adrenergic fibres in the human intestine. Gut 1968; 9: 678-82.

18 Goodrich JT, Bernd P, Sherman D, Gershon MD Phylogeny of enteric serotonergic neurons. 7 Comp Neurol 1980; 190: 15-28

19 Goodrich JT. Serotonergic neurons in human bowel: distribution in congenital megacolon (Hirschsprung's disease) of man and mouse. Gastroenterology 1977; 73: A 868 .

20 Llewellyn-Smith IJ, Furness JB, O'Brien PE, Costa M. Noradrenergic nerves in human small intestine: distribution and ultrastructure. Gastroenterolog. 1984; 87: 513-29.

21 Furness JB, Costa $\mathrm{M}$. The adrenergic innervation of the gastrointestinal tract. Ergeb Physiol 1974; 69: 2-51.

22 Wattchow DA, Furness JB, Costa M. Distribution and coexistence of peptides in nerve fibres of the external muscle of the human gastrointestinal tract. Gastroenterology 1988; 95: 32-41.

23 Gordon-Weeks P, Gabella G. Degeneration of varicose axons and their phagocytosis by smooth muscle cells. 7 Neurocvtol 1977; 6: 711-21.

24 Nishi S, North RA. Presynaptic action of noradrenaline in the myenteric plexus. I Physiol (Lond) 1973; 231: 29P-30P.

25 Hirst GD, McKirdy HC. A nervous mechanism for descending inhibition in guinea-pig small intestine. $\mathcal{f}$ Physiol (Lond) 1974; 238: 129-43.

26 Belai A, Lincoln J, Milner P, Burnstock G. Progressive changes in adrenergic, serotonergic, and peptidergic nerves in proximal colon of streptozotocin diabetic rats. Gastroenterology 1988; 95: 1234-4

27 Garzon J, Holt V, Sanchez-Blazqer P. Neuropeptide Y is an inhibitor of neural function in the mventeric plexus of the guinea-pig ileum. Peptides 1986; 7: 623-9.

28 Holzer P, Lippe IT, Bartho L, Saria A. Neuropeptide Y inhibits excitatory enteric neurons supplying the circular muscle of the guinea-pig small intestine. Gastroenterology 1987; 92: 1944-50.

29 Summers RW, Anuras S, Green J. Jejunal manometry in health, partial intestinal obstruction and pseudoobstruction. Gastroenterology 1983; 85: 1290-300.

30 Bjorklund H, Dahl D, Seiger A. Neurofilament and glial fibrillary acid protein-related immunoreactivity in rodent enteric nervous system. Neuroscience 1984; 12: 277-87.

31 Costa M. Neurofilament immunoreactivity is present in specific subpopulation of guinea-pig enteric neurons. Proc Aust Physiol Pharmacol Soc 1988; 19: $156 \mathrm{P}$

32 Schmidt RE, Plurad SB, Parvin CA, Roth KA. Effect of diabetes and aging on human sympathetic autonomic ganglia. Am $₹$ Pathol 1993; 143: 143-53.

33 Manglia. Am Fathol 993 ; 143: $143-53$. Moreno V, Moncada S, et al. Patients with achalasia lack nitric oxide synthase in the gastro-oesophageal junction. nitric oxide synthase in the gastro-or
Eur 7 Clin Invest 1993; 23: 724-8.

34 Vanderwinden JM, Mailleux P, Schiffmann SN, Vanderhaeghen JJ, De-Laet MH. Nitric oxide synthase activity in infantile hypertrophic stenosis. $N \mathrm{Engl} \mathcal{F ~ M e d}$ 1992; 327: 511-5.

35 Vanderwinden JM, De-Laet MH, Schiffmann SN, Mailleux P, Lowenstein CJ, Snyder SH, et al. Nitric oxide synthase distribution in the enteric nervous system of Hirschsprung's disease. Gastroenterology 1992; 105: 969-73

36 Cortesini $C$, Cianchi F, Infantino A, Lise M. Nitric oxide synthase and VIP distribution in enteric nervous system in idiopathic chronic constipation. Dig Dis Sci 1995; 40: in idiop $2450-5$.

37 Krishnamurthy S, Schuffler MD, Belic L, Schweid AL. An inflammatory axonopathy of the myenteric plexus producing a rapidly progressive intestinal pseudoobstruction. Gastroenterology 1986; 90: 754-8.

38 Chinn JS, Schuffler MD. Paraneoplastic visceral neuropathy as a cause of severe gastrointestinal motor dysfunction. Gastroenterology 1988; 95: 1279-86.

39 Geboes K, Rutgeerts P, Ectors N, Mebis J, Penninckx F, Vantrappen G, et al. Major histocompatibility class II expression on the small intestinal nervous system in Crohn's disease. Gastroenterology 1992; 103: 439-47.

40 Nathan C. Nitric oxide as a secretory product of mammalian cells. FASEB f 1992; 6: 3051-64.

41 Xie Q, Cho HJ, Calaycay J, Mumford RA, Swiderek KM, Lee TD, et al. Cloning and characterisation of inducible nitric oxide synthase from mouse macrophages. Science 1992, 256: 225-8.

42 Arizono N, Matsuda S, Hattori T, Kojima Y, Maeda T, Galli SJ. Anatomical variation in mast cell nerve associations in the rat small intestine, heart, lung, and skin. Similarities of distances between neural processes skin. mast cells, eosinophils, or plasma cells in the jejunal lamina propria. Lab Invest 1990; 62: 626-34. 